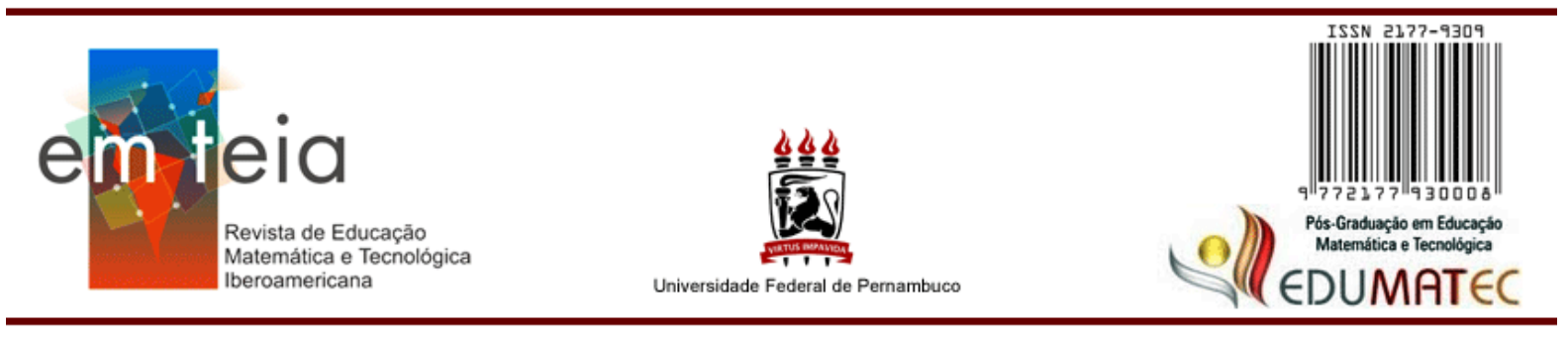

\title{
O ENSINO DE MATEMÁTICA PARA ESTUDANTES COM DEFICIÊNCIA INTELECTUAL SOB AS LENTES DE PESQUISAS BRASILEIRAS
}

\author{
The teaching of mathematics to students with intellectual disabilities under the brazilian \\ research lens
}

\author{
Neusa Eliana Wollmann Tabaka \\ Especialista em Educação Especial e em Psicopedagogia Institucional \\ Universidade Estadual do Paraná/Unespar - Paraná - Brasil \\ neusatabaka@gmail.com \\ Fábio Alexandre Borges \\ Doutor em Educação para a Ciência e a Matemática \\ Universidade Estadual do Paraná/Unespar - Paraná - Brasil \\ fabioborges.mga@hotmail.com \\ Everton José Goldoni Estevam \\ Doutor em Ensino de Ciências e Educação Matemática \\ Universidade Estadual do Paraná/Unespar - Paraná - Brasil \\ evertonjgestevam@gmail.com
}

\section{Resumo}

O presente artigo consiste em uma pesquisa bibliográfica, na qual se analisaram quais aspectos têm sido destacados em investigações brasileiras acerca do ensino de Matemática para estudantes com Deficiência Intelectual (DI). Para tanto, foram considerados artigos publicados em periódicos científicos brasileiros online com foco em Educação Matemática ou Educação Especial, qualificados no Qualis Capes (2013-2016) como A1, A2 e B1, na área de Ensino, num total de 37 periódicos. A partir disso, a seleção dos artigos obedeceu aos seguintes critérios: i) referir-se a pesquisas brasileiras; ii) ter sido publicado entre 2009 a 2019; e iii) conter no resumo ao menos uma das seguintes expressões: "Deficiência Intelectual" ou "Síndrome de Down" (para os periódicos de Educação Matemática); e "Deficiência Intelectual", "Síndrome de Down" ou "Matemática" (para os periódicos de Educação Especial). Com isso, foram selecionados 15 textos, cuja análise foi orientada pela Análise de Conteúdo, a partir das seguintes unidades: i) A inclusão de estudantes com DI nas aulas de Matemática a partir das tarefas proporcionadas; ii) Práticas docentes no ensino de Matemática para estudantes com DI; iii) Uso de abordagens não tradicionais para estudantes com DI; iv) O foco nos conceitos matemáticos dos Anos Iniciais do Ensino Fundamental; e v) O papel do Atendimento Educacional Especializado a estudantes com DI. Os resultados apontam que estudantes com DI têm melhores oportunidades de aprender quando suas diferenças são legitimadas, o que se manifesta particularmente a partir de diversificação metodológica e planejamento pautado nas potencialidades desses aprendizes.

Palavras-Chave: Deficiência Intelectual. Educação Matemática Inclusiva. Pesquisa Bibliográfica. 


\begin{abstract}
This article consists of a bibliographical research in which we sought to analyze which aspects have been highlighted in Brazilian research on the teaching of Mathematics to students with Intellectual Disabilities (ID). For this purpose, articles published in Brazilian online scientific journals focusing on Mathematical Education or Special Education, qualified in Qualis Capes (2013-2016) as A1, A2 and B1, in the area of Education, were considered, totalizing 37 journals. From that point on, the selection of the articles obeyed the following criteria: i) to refer to Brazilian research; ii) to have been published between 2009 and 2019; and iii) to contain in the abstract at least one of the following expressions: "Intellectual Disability" or "Down Syndrome" (for Mathematics Education journals); and "Intellectual Disability", "Down Syndrome" or "Mathematics" (for Special Education journals). Therefore, 15 texts were selected whose analysis was guided by Content Analysis from the following units: i) The inclusion of students with ID in Mathematics classes from the tasks provided; ii) Teaching practices in the teaching of Mathematics for students with ID; iii) The use of non-traditional approaches for students with ID; iv) The focus on mathematical concepts of the Early Years of Elementary School; and v) The role of Specialized Educational Care for students with ID. The results showed that students with ID have better opportunities to learn when their differences are legitimized, which manifests itself particularly from methodological diversification and planning based on the potential of these learners.
\end{abstract}

Keywords: Intellectual Disability. Inclusive Mathematics Education. Bibliographical Research.

\title{
Introdução
}

A história do processo de escolarização do estudante com deficiência foi marcada, em boa parte, pela segregação ou mesmo a exclusão. Porém, com o advento da inclusão, tem-se buscado defender e discutir as condições adequadas para a aprendizagem desses estudantes, condizentes com suas necessidades educativas e que destacam, mais recentemente, suas potencialidades ao invés das deficiências.

Atualmente, defende-se a educação dos estudantes com deficiência em uma perspectiva inclusiva, o que está garantido, dentre outros documentos, pela Política Nacional de Educação Especial na Perspectiva da Educação Inclusiva (BRASIL, 2008b). Nessa política, assegura-se inclusão escolar de alunos com deficiência, transtornos globais do desenvolvimento e altas habilidades/superdotação, entendendo que as deficiências devem ser reconhecidas, porém, devem ser concebidas atreladas às barreiras impostas pelos contextos em que todos estamos envolvidos. Assim, não basta falar em estudante com deficiência, mas entender que as deficiências se manifestarão em maior ou menor grau a partir das adequações no contexto onde todos estão incluídos. Nesse sentido, o presente estudo focaliza estudantes com deficiência intelectual (DI) ${ }^{1}$ e a relação com o ensino e a aprendizagem de Matemática.

$1 \mathrm{O}$ uso do referido termo vem sendo indicado pela Associação Americana de Deficiência Intelectual e Desenvolvimento (AADID). De acordo com a entidade, a deficiência intelectual caracteriza-se por "limitações significativas tanto no funcionamento intelectual como na conduta adaptativa e está expresso nas habilidades práticas, sociais e conceituais, originando-se antes dos dezoito anos de idade" (AADID, 2010, p. 31). Para uma definição mais detalhada do conceito, ver Pletsch e Oliveira (2013). 
A American Psychiatric Association (APA, 2013) caracteriza a pessoa com DI por déficits de habilidades mentais gerais, tais como raciocínio, resolução de problemas, planejamento, pensamento abstrato, julgamento e aprendizagem escolar. Por conseguinte, pessoas com DI podem apresentar maior dificuldade em Matemática. As pessoas que não apresentam limitações cognitivas são capazes de contar e de fazer cálculos envolvendo operações matemáticas simples, mesmo antes de ingressarem na escola (CARRAHER; SCHLIEMANN; CARRAHER, 2001), o que não ocorre com aquelas com DI, o que se constitui como mais uma particularidade a ser considerada por todos os envolvidos no atendimento desses estudantes no ambiente escolar.

A Matemática é de relevância para a vida e autonomia das pessoas, o que se evidencia pela frequência com que somos requisitados a utilizar e compreender números, reconhecer formas, lidar com medidas e realizar cálculos em tarefas fundamentais da vida cotidiana, desde identificar o horário no relógio, entender uma receita de bolo, identificar o número de um calçado ou telefone, realizar compras, organizar espaços físicos, entre inúmeras outras situações cotidianas.

Costa (2018) afirma que a Matemática ensinada para o estudante com DI deve ser a mesma que é ensinada para todos. Complementamos ainda que, indiferente da escola que o estudante com DI frequente, seja ela inclusiva ou especializada, as especificidades do indivíduo devem ser reconhecidas e atendidas, para que ele tenha oportunidade de desenvolver os conhecimentos matemáticos necessários e relevantes para a maioria das pessoas.

Acreditamos que muitos professores que ensinam Matemática ${ }^{2}$ para estudantes com DI traduzem em suas práticas mudanças atitudinais e inovações didáticas e pedagógicas necessárias para o processo de aprendizagem desses estudantes. Contudo, há ainda uma lacuna na divulgação dessas experiências para outros profissionais interessados na temática. Nesse sentido, percebemos a necessidade de discutir essas experiências através do presente estudo, como uma síntese do que vem sendo realizado e destacado nas investigações envolvendo essa temática. Isso posto, este estudo se traduz na motivação e na preocupação em selecionar, elencar e discutir, por meio de uma pesquisa bibliográfica sistematizada, os principais aspectos proeminentes das pesquisas que envolvem o ensino de Matemática para

\footnotetext{
2 Por professores que ensinam Matemática são compreendidos todos os profissionais que atuam no ensino de Matemática como professores, nos diversos níveis de ensino, independente de sua formação na licenciatura em Matemática ou em outro curso correlato como Pedagogia, Formação Docente (Magistério), Engenharia, Administração etc.
} 
estudantes com $\mathrm{DI}^{3}$ no contexto brasileiro.

Decorrente a isso, a problemática aqui apresentada é: quais aspectos têm sido destacados pelas pesquisas brasileiras que tratam do ensino de Matemática para estudantes com DI? Por se tratar de uma pesquisa de cunho bibliográfico, optamos por não trazer uma seção de revisão teórica, a qual será realizada no decorrer da própria análise de dados. $\mathrm{Na}$ sequência, apresentamos o percurso metodológico que orienta o estudo.

\section{Percurso metodológico}

Nossa investigação se insere como uma pesquisa do tipo bibliográfica. Embora toda pesquisa exija o ato de buscar referenciais teóricos que contribuam com as etapas da investigação, em algumas delas o desenvolvimento se dá exclusivamente a partir de fontes bibliográficas, e é nessa perspectiva que se alicerça este trabalho (GIL, 2002).

A elaboração do corpus analítico da pesquisa admitiu como critério inicial periódicos brasileiros online das áreas de Educação Matemática ou Educação Especial, considerando nosso interesse por textos que tratassem do ensino e da aprendizagem de Matemática para/por estudantes com DI. Para a seleção dos periódicos, realizamos duas ações complementares: primeiramente, consideramos os periódicos brasileiros divulgados no site da Sociedade Brasileira de Educação Matemática (SBEM) Plataforma Sucupira ${ }^{5}$ em busca de periódicos qualificados com os estratos A1, A2 e B1 na área de Ensino, no quadriênio 2013-2016 (também considerando as áreas de Educação Matemática ou Educação Especial). Oriundos destes critérios e procedimentos de seleção, obtivemos um total de 37 periódicos, a saber, 34 de Educação Matemática e 3 de Educação Especial.

$\mathrm{Na}$ sequência, selecionamos os textos nessas revistas a serem analisados conforme o nosso objetivo. Para tanto, optamos pela busca de palavras-chave no resumo dos artigos. Nos periódicos de Educação Matemática, as palavras de busca foram: "Deficiência Intelectual" ou “Síndrome de Down”; nos periódicos de Educação Especial, as palavras foram: "Deficiência

\footnotetext{
${ }^{3}$ Considerando estimativas do IBGE, em que mais de 300 mil pessoas têm a síndrome de Down (SD) no Brasil, e sabendo que a maioria dos estudantes com SD apresentam DI, houve a necessidade de incluir nas buscas a expressão síndrome de Down.

${ }^{4}$ http://www.sbembrasil.org.br/sbembrasil/index.php/95-periodicos/117-periodicos. Busca em 11 de abril de 2020.

${ }^{5} \mathrm{https}$ //sucupira.capes.gov.br/sucupira/public/consultas/coleta/veiculoPublicacaoQualis/listaConsultaGeralPerio dicos.jsf. Busca em 11 de abril de 2020.
} 
Intelectual", "Matemática" ou "Síndrome de Down”. Foram encontrados 166 artigos. Porém, esse filtro permitiu que fossem selecionados textos que não tratavam especificamente do ensino e da aprendizagem de Matemática para estudantes com DI como foco principal, mas como fatores secundários. Então, um último critério empregado na seleção consistiu em observar os objetivos dos artigos desconsiderando aqueles que não envolvessem explicitamente o ensino e/ou a aprendizagem de Matemática e a DI. Do emprego deste último critério resultaram 15 artigos que são apresentados no Quadro 1 e que constituem o corpus analítico do presente estudo.

Quadro 1 - Relação de artigos que constituem o corpus analítico de estudo sobre o ensino e/ou a aprendizagem de Matemática para/por estudantes com DI

\begin{tabular}{|c|c|c|c|}
\hline $\begin{array}{l}\mathbf{N}^{0} . \\
\text { Id. }\end{array}$ & Título do Artigo & Autores/Ano & Objetivos Gerais \\
\hline 1 & $\begin{array}{l}\text { Deficiência intelectual e aquisição } \\
\text { matemática: currículo como rede de } \\
\text { relações condicionais }\end{array}$ & $\begin{array}{l}\text { Rossit e } \\
\text { Goyos } \\
(2009)\end{array}$ & $\begin{array}{c}\text { Analisar a aquisição de relações } \\
\text { matemáticas e apresentar um currículo } \\
\text { baseado no paradigma de equivalência de } \\
\text { estímulos para ensinar estudantes com DI a } \\
\text { manusear dinheiro. }\end{array}$ \\
\hline 2 & $\begin{array}{l}\text { Salas de recursos e o uso de jogos para o } \\
\text { ensino de conceitos matemáticos }\end{array}$ & $\begin{array}{l}\text { Albuquerque, } \\
\text { Mori e } \\
\text { Lacanallo } \\
\text { (2009) }\end{array}$ & $\begin{array}{l}\text { Investigar a prática pedagógica } \\
\text { em Salas de Recursos (SR). }\end{array}$ \\
\hline 3 & $\begin{array}{c}\text { Eixos convergentes na aprendizagem } \\
\text { matemática de alunos com síndrome de } \\
\text { Down }\end{array}$ & $\begin{array}{l}\text { Groenwald et } \\
\text { al. }(2010)\end{array}$ & $\begin{array}{c}\text { Identificar os eixos convergentes na } \\
\text { aprendizagem Matemática de alunos com } \\
\text { SD. }\end{array}$ \\
\hline 4 & $\begin{array}{c}\text { Concepção dos professores sobre a } \\
\text { apropriação de conhecimentos } \\
\text { matemáticos por crianças com síndrome } \\
\text { de Down }\end{array}$ & $\begin{array}{l}\text { Silva e } \\
\text { Oliveira } \\
(2010)\end{array}$ & $\begin{array}{l}\text { Compreender, a partir da concepção dos } \\
\text { professores, como ocorrem o acesso e a } \\
\text { apropriação de conhecimentos matemáticos } \\
\text { por crianças com síndrome de Down (SD) a } \\
\text { partir da sua participação no contexto de } \\
\text { sala de aula dos anos iniciais do Ensino } \\
\text { Fundamental }\end{array}$ \\
\hline 5 & $\begin{array}{l}\text { Contagem numérica em estudantes com } \\
\text { síndromes de X-Frágil e Prader-Willi }\end{array}$ & $\begin{array}{l}\text { Dorneles } \\
(2012)\end{array}$ & $\begin{array}{l}\text { Investigar as características dos princípios } \\
\text { da contagem numérica por } 2 \text { estudantes: um } \\
\text { com síndrome do X-Frágil (SXF) e outro } \\
\text { com síndrome de Prader-Willi (SPW). }\end{array}$ \\
\hline 6 & $\begin{array}{c}\text { A inclusão de alunos portadores de } \\
\text { deficiência intelectual e/ou paralisia } \\
\text { cerebral em salas de aula regulares de } \\
\text { matemática }\end{array}$ & Zuffi (2014) & $\begin{array}{l}\text { Analisar a inclusão de alunos com } \\
\text { necessidades especiais em salas de aula } \\
\text { regulares de Matemática. }\end{array}$ \\
\hline 7 & $\begin{array}{c}\text { Contribuições da neurociência para a } \\
\text { educação matemática de uma pessoa com } \\
\text { necessidades educativas especiais } \\
\text { intelectivas }\end{array}$ & $\begin{array}{l}\text { Seibert e } \\
\text { Groenwald } \\
(2014)\end{array}$ & $\begin{array}{l}\text { Qualificar a autonomia do estudante em } \\
\text { Matemática, implementando uma sequência } \\
\text { didática eletrônica individualizada. }\end{array}$ \\
\hline 8 & $\begin{array}{l}\text { Ensino da matemática a alunos com } \\
\text { deficiência intelectual na educação de } \\
\text { jovens e adultos }\end{array}$ & $\begin{array}{c}\text { Brito, } \\
\text { Campos e } \\
\text { Romanatto } \\
(2014)\end{array}$ & $\begin{array}{c}\text { Conhecer as práticas do } \\
\text { professor da EJA para o ensino de saberes } \\
\text { matemáticos ao aluno jovem e adulto com } \\
\text { deficiência intelectual, e intervir junto ao } \\
\text { docente sobre possíveis estratégias que } \\
\text { seriam então adotadas. }\end{array}$ \\
\hline 9 & $\begin{array}{l}\text { O Aluno com Deficiência Intelectual e a } \\
\text { Resolução de Problemas }\end{array}$ & $\begin{array}{c}\text { Costa e } \\
\text { Souza }(2015) \\
\end{array}$ & $\begin{array}{c}\text { Investigar o processo de resolução de } \\
\text { problemas por alunos com DI no âmbito da }\end{array}$ \\
\hline
\end{tabular}




\begin{tabular}{|c|c|c|c|}
\hline & & & Sala de Recurso Multifuncional (SRM). \\
\hline 10 & $\begin{array}{l}\text { O ensino da matemática ao deficiente } \\
\text { intelectual: projetos de trabalho em uma } \\
\text { perspectiva contextualizada e } \\
\text { interdisciplinar }\end{array}$ & $\begin{array}{l}\text { Miranda e } \\
\text { Pinheiro } \\
(2016)\end{array}$ & $\begin{array}{l}\text { Discutir a ressignificação do processo } \\
\text { ensino e aprendizagem de Matemática e } \\
\text { Ciências de alunos com DI ao aplicar um } \\
\text { projeto interdisciplinar. }\end{array}$ \\
\hline 11 & $\begin{array}{c}\text { Ensino de números naturais associado à } \\
\text { literatura infantil para alunos com } \\
\text { Síndrome de Down }\end{array}$ & $\begin{array}{l}\text { Valverde; } \\
\text { Sousa e } \\
\text { Santos } \\
(2017)\end{array}$ & $\begin{array}{c}\text { Investigar o uso da literatura infantil } \\
\text { associada a jogos como recurso } \\
\text { metodológico para ensino de números } \\
\text { inteiros para estudante com Síndrome de } \\
\text { Down (SD). }\end{array}$ \\
\hline 12 & $\begin{array}{l}\text { Avaliação de habilidades matemáticas } \\
\text { em crianças com síndrome de Down e } \\
\text { com desenvolvimento típico. }\end{array}$ & $\begin{array}{l}\text { Costa, } \\
\text { Picharillo } \\
\text { e Elias } \\
(2017)\end{array}$ & $\begin{array}{l}\text { Avaliar as habilidades matemáticas em } 11 \\
\text { crianças com síndrome de Down (SD) e dez } \\
\text { com desenvolvimento típico, com idade } \\
\text { entre seis e dez anos, nos aspectos discretos } \\
\text { e contínuos. }\end{array}$ \\
\hline 13 & $\begin{array}{l}\text { Construção mediada e colaborativa de } \\
\text { instrumentos de avaliação da } \\
\text { aprendizagem na escola inclusiva }\end{array}$ & $\begin{array}{l}\text { Mello e } \\
\text { Hostins } \\
(2018)\end{array}$ & $\begin{array}{c}\text { Discutir a potência da construção mediada } \\
\text { de instrumentos de avaliação de } \\
\text { aprendizagem entre professores do ensino } \\
\text { comum e do Atendimento Educacional } \\
\text { Especializado - AEE para a inclusão } \\
\text { escolar. }\end{array}$ \\
\hline 14 & $\begin{array}{c}\text { Fenomenologia e Filosofia } \\
\text { Existencialista de Heidegger no estudo } \\
\text { de um deficiente intelectual e suas } \\
\text { dificuldades na aprendizagem de } \\
\text { matemática }\end{array}$ & $\begin{array}{l}\text { Modenutte, } \\
\text { Monteiro e } \\
\text { Susiki (2019) }\end{array}$ & $\begin{array}{l}\text { Compreender como uma docente produziu a } \\
\text { interação entre professor da sala, estudante } \\
\text { e objeto de ensino, de modo que a prática } \\
\text { pedagógica fosse significativa e efetiva para } \\
\text { todos. }\end{array}$ \\
\hline 15 & $\begin{array}{c}\text { Neuroplasticidade na Educação e } \\
\text { Reabilitação Cognitiva da Deficiência } \\
\text { Intelectual }\end{array}$ & $\begin{array}{l}\text { Freitas e } \\
\text { Ribeiro } \\
(2019)\end{array}$ & $\begin{array}{c}\text { Descrever brevemente o perfil funcional da } \\
\text { DI, demonstrando técnicas que favorecem a } \\
\text { adaptação curricular para essas crianças ao } \\
\text { estabelecer a relação entre educação e } \\
\text { neuroplasticidade. }\end{array}$ \\
\hline
\end{tabular}

Para a análise dos dados, optamos por elementos da Análise de Conteúdo, segundo os pressupostos de Moraes (1999). Para esse autor, a Análise de Conteúdo se constitui em uma metodologia de pesquisa utilizada na descrição e interpretação de documentos e textos das mais diversas classes. Nesse sentido, nossa opção foi pela definição de unidades de análise. Para tanto, na fase de preparação e organização das informações, elencamos os objetivos gerais dos 15 estudos presentes nos resumos de cada um deles em busca da convergência de temáticas, sendo que, em caso de dois ou mais textos com uma mesma temática, geramos uma unidade de análise. Nossas unidades de análise foram definidas, portanto, a posteriori, a partir da convergência de temáticas trazidas nos objetivos gerais dos 15 artigos analisados, na seguinte conformidade: i) A inclusão de estudantes com DI nas aulas de Matemática a partir das tarefas proporcionadas; ii) Práticas docentes no ensino de Matemática para estudantes com DI; iii) Uso de abordagens não tradicionais para estudantes com DI; iv) O foco nos conceitos matemáticos dos anos iniciais do Ensino Fundamental e v) O papel do atendimento educacional especializado junto a estudantes com DI.

$\mathrm{Na}$ sequência, apresentamos as unidades de análise, que constituem a etapa de 
descrição do método de Análise de Conteúdo (MORAES, 1999). Cabe salientar, contudo, que o estudo completo do artigo apontou que um mesmo trabalho pode apresentar aspectos para mais de uma unidade, o que foi considerado na etapa de descrição. Por fim, considerando o método de Análise de Conteúdo, a etapa de interpretação complementa as descrições presentes nas análises, particularmente nas sínteses que apresentarem os principais aspectos por nós identificados e suas contribuições no que concerne à temática em enfoque em referência ao objetivo geral do estudo.

\section{A inclusão de estudantes com deficiência nas aulas de Matemática a partir das tarefas proporcionadas}

Os artigos que contribuíram mais diretamente com a presente unidade de análise foram os de $n^{\circ} 4,6,9,10,12,14,15^{6}$. Rodrigues (2006) aponta que, no campo educacional, uma escola inclusiva, que pretende seguir uma política nessa perspectiva, deve desenvolver políticas, culturas e práticas valorizando o contributo ativo de cada aluno para a elaboração de um conhecimento construído e partilhado e, dessa forma, atingir a qualidade acadêmica e sociocultural de todos, sem discriminação. Vale acrescentar que estudantes com DI podem ser caracterizados por limitações nas habilidades mentais gerais e essas habilidades estão ligadas à inteligência. Portanto, estudantes com essa deficiência tendem a apresentar dificuldades nas aulas de Matemática. Nesse sentido, destacamos a importância dessa unidade de análise, em que sintetizamos os referenciais que apontam discussões que corroborem essa temática, mais especificamente com relação à inclusão desses estudantes diante dessas dificuldades.

O estudo de Zuffi (2014) partiu de três casos de inclusão de estudantes com DI e surdez em salas de aula de escolas públicas regulares dos anos finais do Ensino Fundamental e do Ensino Médio. A autora constatou que ainda persiste a "exclusão no interior", com pouco interesse dos professores em promover o desenvolvimento de todos os estudantes, visto que muitos não acompanhavam as tarefas propostas para a série, bem como as adaptações necessárias às particularidades dos estudantes envolvidos nos estudos não eram realizadas. Outro aspecto destacável foi o fato de que o planejamento do ensino e da aprendizagem, quando da presença de estudantes com deficiência, deve ser voltado para toda a turma, caso se almeje de fato a inclusão de todos, conciliando as necessidades específicas de todos os

\footnotetext{
${ }^{6}$ Em cada unidade de análise, nem todos os textos serão apresentados, mas alguns selecionados para ilustrar nosso debate na respectiva unidade.
} 
estudantes.

No estudo de Modenutte, Monteiro e Susiki (2019) foram investigadas as trajetórias adotadas por uma professora de Matemática (professora de apoio) que acompanhava um estudante com 19 anos de idade com DI. Na escola, esse estudante era visto pelos seus colegas como um indivíduo incapaz de desempenhar as atividades propostas. Tal característica mudou com o início do trabalho de uma professora de apoio, a qual desenvolveu tarefas voltadas para a melhoria do desempenho em leitura e raciocínio matemático. Os autores apontam a melhoria significativa no desempenho do estudante diante da resolução de problemas de adição e subtração no decorrer de três atividades. Esse estudo concluiu que o estabelecimento de uma boa relação entre estudante e professor, oportunizando tarefas e temporalidades adequadas, mostrou a capacidade do estudante em desenvolver-se. Por conseguinte, o estudo também evidencia a importância de considerar a necessidade dos professores que, além dos conhecimentos de técnicas e estratégias variadas de ensino, precisam conhecer as especificidades dos estudantes.

Valverde, Souza e Santos (2017) trabalharam com um estudante com SD, de uma escola estadual de ensino regular. Foram realizadas atividades pedagógicas em que o estudante apresentou pouco conhecimento numérico. Na sequência, foram desenvolvidas sessões individuais no contraturno das aulas regulares, objetivando ampliar o conhecimento de quantificação dos números. Concomitantemente, desenvolveu-se o que os autores chamaram de "produto educacional", que consistiu em um livro literário, um jogo de cartas, um dominó e um software, que podem ser utilizados de diversas maneiras como recurso metodológico. Um fator constatado durante a pesquisa foi a necessidade de respeitar e valorizar as particularidades dos estudantes. Uma metodologia ou recurso didático não pode ser considerado como adequado a todos os alunos, mas pode ser experimentado por todos.

Mello e Hostins (2018) conduziram um trabalho de construção coletiva e mediada por um Plano Colaborativo de Atendimento Educacional para uma estudante com DI do $6^{\circ}$ ano do Ensino Fundamental. Participaram da investigação sete professores das áreas de Língua Portuguesa, Geografia, História, Matemática, Artes, Ciências, Educação Física e duas da Educação Especial, que juntos desenvolveram dinâmicas de estudo e definição de conceitos, procedimentos e instrumentos diferenciados de avaliação pedagógica. Foram organizados estudos e aplicações de atividades práticas na sala de aula para a estudante nas disciplinas de responsabilidade de cada um dos professores. Tais estudos e tarefas tinham o propósito de produzir saberes e referenciais teórico-metodológicos que subsidiaram a investigação do 
processo de ensino e aprendizagem dessa estudante, tanto na sala de aula comum como no Atendimento Educacional Especializado e que possibilitasse a construção mediada de instrumento de avaliação, a partir de práticas colaborativas entre esses professores. Os resultados apontaram que a inclusão pode acontecer de forma significativa quando há uma construção de alternativas metodológicas consistentes e que tal consistência pode vir de maneira colaborativa entre os professores envolvidos.

Três professoras de escolas públicas que trabalham com estudantes com SD (8 a 10 anos de idade do $1^{\circ}$ e $2^{\circ}$ ano do Ensino Fundamental) participaram do estudo de Silva e Oliveira (2010) por meio de entrevistas semiestruturadas. Os resultados da investigação indicaram "que as crianças com SD não estão tendo acesso e muito menos se apropriando de conceitos matemáticos” (p. 269), uma vez que as práticas das professoras se limitavam à exposição oral para ensinar todos os estudantes, inclusive os com $\mathrm{SD}$, negando suas especificidades ou a de qualquer outro. Diante disso, as pesquisadoras inferem que, para se construir práticas inclusivas no ensino de Matemática, exige-se o reconhecimento dos estudantes como participantes ativos do processo de aprendizagem e, acima de tudo, é necessário que os professores reconheçam a diversidade e a heterogeneidade dos grupos humanos como pré-requisitos à construção de um ambiente motivador para os seus desenvolvimentos.

Rosso e Dorneles (2012) analisaram a inclusão de dois estudantes, um com síndrome do X-Frágil (SXF) e outro com síndrome de Prader-Willi (SPW), em salas regulares. Os resultados sugerem que as características cognitivas e comportamentais dos estudantes não são suficientes para garantir o sucesso escolar na perspectiva inclusiva. Eles enfatizam que é preciso investigar como esses estudantes constroem conceitos e significam conteúdos presentes na estrutura curricular, em especial aqueles relativos à Matemática, para prover recursos específicos que garantam aprendizagens desses estudantes.

Freitas e Ribeiro (2019) evidenciam que a DI pode impactar severamente os aspectos educacionais, porém, a inclusão escolar cria a oportunidade de inserir esses estudantes no ensino regular. Para tanto, é necessário o suporte de outras áreas do conhecimento, como a neuropsicologia e a psicologia comportamental. Assim, espera-se uma maior difusão de um modelo multidisciplinar para auxiliar a formação do conhecimento de profissionais que lidam com a educação de estudantes com DI. As autoras salientam que intervenções psicoeducacionais precisam ser pensadas e planejadas de forma individualizada, direcionando para as necessidades de cada estudante. Deste modo, as práticas pedagógicas utilizadas devem 
proporcionar não apenas um ambiente adequado para a socialização, mas acima de tudo um ambiente de aprendizagem.

Percebemos, mediante os estudos apresentados nessa unidade, que alguns estudantes com DI não foram contemplados nos processos de ensino e, por conseguinte, de aprendizagem. Portanto, esses estudantes não foram incluídos se pensarmos que o objetivo principal da escola é discutir novos conhecimentos com todos e com boa qualidade. Paralelamente a isso, evidenciamos que alguns professores alcançaram êxito quando, ao olhar para o estudante com DI, enxergaram suas particularidades, considerando o potencial desse estudante e utilizando práticas adequadas. Essa adequação deve considerar a temporalidade, as diversas áreas do conhecimento, uma articulação entre as práticas desenvolvidas pelos diferentes professores nas várias disciplinas envolvidas no processo de escolarização, bem como os modos como os estudantes com DI constroem os conceitos matemáticos (em nosso caso) e compreendem os conteúdos de Matemática do currículo da Educação Básica. Por fim, a própria relação do estudante com DI com o professor e com a turma ganha relevo, devendo as práticas realizadas favorecerem sua participação mais ativa e efetiva nos processos de ensino e de aprendizagem. Isso se justifica por entendermos que a inclusão deve partir não somente de atitudes ou de respeito à legislação, mas dos tipos de tarefas proporcionadas em uma sala de aula.

\section{Práticas docentes no ensino de Matemática para estudantes com deficiência intelectual}

Consideramos nesta unidade os artigos de $n^{\circ} 1,2,5,6,7,10,11,13$ e 15, cujos enfoques perpassam discussões abordando a prática docente frente ao desafio educativo envolvendo estudantes com DI no ensino de Matemática.

Costa e Souza (2015) discutem a proposição de uma situação problema para um grupo de alunas do $5^{\circ}$ ano do Ensino Fundamental que frequentava a Sala de Recursos Multifuncionais com diagnóstico de $\mathrm{DI}^{7}$. Para tal, foram disponibilizados diferentes materiais como caneta, papel, desenhos, balas etc. para auxiliar na resolução. As estudantes podiam trabalhar juntas, discutirem e construírem as possíveis soluções. A professora mediava as interações, criando novas oportunidades de reflexões. Essa prática evidenciou que o docente, ao utilizar a Resolução de Problemas no ensino de Matemática com apoio e disponibilização de diferentes materiais, estimula o desenvolvimento, a reflexão e promove autonomia e

\footnotetext{
${ }^{7}$ No texto original, não foi especificada a quantidade de participantes.
} 
confiança na capacidade de pensar matematicamente dos estudantes.

A pesquisa de Modenutte, Monteiro e Susiki (2019) sinaliza a importância dos professores em entender a subjetividade e as diferenças com relação aos tempos de aprendizagem de cada estudante, que seriam tempos diferentes particularmente daquele com DI. No caso específico desta pesquisa, os autores salientam que a professora não possuía formação específica para trabalhar com estudantes com deficiência. No entanto, ela reconhecia a importância de estabelecer vínculos e laços emocionais, possibilitando, assim, as oportunidades mais amplas para atuação do estudante nas tarefas propostas. Corroboramos os autores que é necessário considerar a ampliação de oportunidades de formação para os professores, assim como é fundamental que os professores apresentem uma sensibilidade para perceber no estudante suas particularidades e necessidades específicas.

O estudo de Miranda e Pinheiro (2016) foi desenvolvido em uma escola na modalidade de Educação Especial na área de deficiência intelectual e múltiplas deficiências, com a participação de seis estudantes (idades entre 10 e 12 anos) do $2^{\circ}$ ano do Ensino Fundamental. Com o propósito de desenvolver uma prática pedagógica interdisciplinar (Ciências e Matemática), o projeto foi iniciado com a definição do tema entre o professor e os estudantes. O tema foi "Preparação de uma refeição", e o papel da professora foi de orientálos na organização das ideias por meio de questionamentos. Evidenciou-se que a professora e os estudantes elaboraram e executaram o planejamento, tendo como referência o interesse e as necessidades dos estudantes. Nessa perspectiva, é importante que os professores utilizem tarefas que favoreçam as construções dos conceitos matemáticos alicerçados em situações do cotidiano, permeando as necessidades dos estudantes enquanto cidadãos.

Seibert e Groenwald (2014) apresentam resultados de um estudo de caso de um estudante de 14 anos de idade, do $7^{\circ}$ ano do Ensino Fundamental, com Espinha Bífida e que apresenta DI. As autoras enfatizam que diferentes recursos didáticos podem ser agregados à prática dos professores, proporcionando um ambiente motivador e facilitador do processo de aprendizagem de Matemática. Salientam ainda que o professor precisa compreender as diferentes maneiras de aprender e as formas pessoais de aprendizado de todos os estudantes. Com a pesquisa, ficou evidenciado que, com o uso de estratégias didáticas diferenciadas, que proporcionam diferentes estímulos e modificam os mecanismos de aprendizagem, pode ser possível alterar a estrutura do Sistema Nervoso Central (SNC) através da plasticidade cerebral, ocorrendo uma repaginação do movimento cerebral e proporcionando uma maior capacidade de aprendizagem. 
A pesquisa de Albuquerque, Mori e Lacanallo (2009) investigou a prática pedagógica em Salas de Recursos (SR) para alunos de $5^{\mathrm{a}}$ à $8^{\mathrm{a}}$ Séries (atuais $6^{\circ}$ ao $9^{\circ}$ anos do Ensino Fundamental), a qual objetivava dar apoio especializado a alunos com distúrbios de aprendizagem ou DI, matriculados em classes comuns da rede regular de ensino. Os dados de campo foram colhidos com observações em sala de aula e entrevistas com os professores das SR em três escolas da rede pública estadual. Os resultados indicaram uma expressiva utilização do jogo no ensino de Matemática, porém, as observações e entrevistas evidenciaram a prevalência dos jogos como um recurso de compensação e passatempo nas aulas de Matemática da SR e, portanto, sem relação com os planejamentos docentes. Em contrapartida, as autoras afirmam que o jogo, se utilizado de forma planejada, organizada e intencional, constitui-se em instrumento importante para o professor, como recurso no desenvolvimento da aprendizagem dos estudantes com DI, particularmente.

Silva e Oliveira (2010), ao trazer os resultados de entrevistas semiestruturadas com três professoras que, entre seus estudantes, têm também algum(uns) com SD, apontam que esses estudantes não estão tendo acesso e muito menos estão se apropriando de conceitos matemáticos (no contexto investigado), uma vez que a prática das professoras têm se limitado à exposição oral para ensinar todos os estudantes, inclusive aqueles com SD, negando suas especificidades e evidenciando, assim, a homogeneização tanto do ensino quanto da aprendizagem.

Participaram da pesquisa de Rossit e Goyos (2009) 11 pessoas com DI, com idades entre 9 e 32 anos, estudantes de uma escola especializada. O procedimento de ensino foi conduzido através do programa computacional Mestre ${ }^{\circledR}$. $\mathrm{O}$ modelo apresentado na pesquisa configurou-se como uma estratégia promissora e viável para ser empregada também em ambientes educacionais inclusivos, pois atendeu às necessidades educacionais de todos os estudantes. Cabe aos educadores, de acordo com os autores, inteirarem-se das inovações produzidas na área da Educação Especial e aplicá-las em salas de aula, sejam elas comuns ou da Educação Especial.

Freitas e Ribeiro (2019) colaboram também nessa unidade de análise ao apresentarem uma relação entre educação e reabilitação cognitiva que demonstra a importância do conhecimento sobre o desenvolvimento neurocognitivo para os professores que atuam com a educação de estudantes com a DI. As autoras afirmam que a aplicação de um modelo inclusivo efetivo ainda carece de uma formação pedagógica mais dinâmica e multidisciplinar. Elas acrescentam que o conhecimento da capacidade plástica do cérebro é indispensável para 
profissionais que trabalham com o processo de desenvolvimento de funções cognitivas em crianças com DI e, para isso, devem ser feitas adaptações individualizadas considerando as necessidades e capacidades de cada estudante. Adaptar o currículo para a aprendizagem de um estudante com DI implica estabelecer situações de aprendizagem capazes de estimular e de promover o desenvolvimento cognitivo, emocional e social.

A síntese dos estudos desta unidade aponta que o professor assume um compromisso com a educação e há a necessidade de formações mais adequadas para o atendimento às necessidades educacionais especiais. A neurociência parece se mostrar campo promissor a ser incorporado a essas formações, porque colabora para compreensão dos processos de aprendizagem, evidenciando o potencial de diferentes recursos para o atendimento das especificidades do estudante com DI, bem como apontando estímulos capazes de modificar os mecanismos de aprendizagem. Esses aspectos podem apontar, por exemplo, modos como as práticas de ensino podem articular os conhecimentos matemáticos em situações cotidianas que favoreçam a compreensão dos alunos, bem como a ressignificação do papel pedagógico dos jogos, para além da simples função de passatempos e compensações.

Corroboramos a premissa de que o professor necessita constantemente (re)ver e adequar suas ações para atender a "todos" os estudantes e que compreender a diversidade de demandas não é tarefa fácil. Deste modo, é patente formações que promovam conhecimento e desenvolvam as sensibilidades desses profissionais para a insuficiência das práticas orais de ensino, e a necessidade de práticas diferenciadas, que manifestam a adequação do currículo às singularidades dos estudantes, capazes de estimulá-los e de promover desenvolvimento cognitivo, emocional e social. Em paralelo, é fundamental a percepção e crença de que cada estudante tem seu potencial, o qual deve ser explorado para garantir seu direito de aprendizagem.

\section{O uso de abordagens não tradicionais para estudantes com deficiência intelectual}

Compreendemos que os artigos de $\mathrm{n}^{\circ} 2,3,5,7,11,12,13$ e 14 colaboram mais diretamente com essa unidade de análise. Inicialmente, importa assumir uma concepção de ensino tradicional, já que queremos aqui apresentar o oposto disso, ou seja, abordagens não tradicionais para estudantes com DI. Segundo Mizukami (1986), o ensino tradicional é centrado no professor como transmissor de informações ou conhecimentos. $\mathrm{O}$ aluno apenas executa e acumula conhecimentos, prescrição que lhe é ofertada por autoridades exteriores, 
sendo ignoradas as diferenças individuais. Com isso, tem-se a preocupação mais com a quantidade e uniformização de conceitos e aprendizagens do que com o pensamento individual. Deste modo, esta unidade sintetiza contribuições dos estudos que exemplificam abordagens que se contrapõem à perspectiva tradicional, com discussões particulares ao contexto e às necessidades de estudantes com DI.

Na pesquisa de Costa e Souza (2015), estudantes do $5^{\circ}$ ano do Ensino Fundamental, participantes da Sala de Recursos Multifuncionais, receberam um problema que poderiam discutir em grupo acerca das possíveis soluções, experimentando e refletindo de forma contextualizada com uso de diferentes materiais e recursos (material manipulativo como balas, calculadora, desenho de caixas, lápis e papel). As autoras sugerem que o uso de diferentes estratégias na aprendizagem da Matemática, principalmente para estudantes com DI, auxilia no processo de abstração do pensamento, evitando a, somente, aplicação direta de uma operação matemática.

Os sujeitos da pesquisa de Groenwald et al. (2010) foram dois indivíduos com SD, com 21 e 29 anos de idade. Foi utilizado o Sistema Tutorial Inteligente (ITS, na sigla em inglês), que se trata de um software baseado em um modelo educativo fundamentado nas teorias construtivista e de aprendizagem colaborativa. O ITS é um software matemático que atua como um tutorial, que dirige o ensino do usuário, sendo denominado inteligente por abordar a técnica de Inteligência Artificial. O ITS “é capaz de adaptar-se, tanto ao conteúdo propriamente dito, quanto à estratégia de ensino, conforme as características, necessidades e expectativa de cada estudante, gerando uma sequência de ações individualizadas" (GROENWALD et al., 2010, p. 29). Os autores acrescentam que é "necessário que se respeitem as características cognitivas dos estudantes próprias da idade, partindo dos conhecimentos prévios que eles possuem, por isso, contém atividades motivadoras relacionadas com o entorno do estudante" (p. 29).

No projeto interdisciplinar já mencionado aqui de Miranda e Pinheiro (2016), ganha destaque o fato de que a escolha dos temas a serem abordados contou com a colaboração de todos, inclusive dos estudantes. Todas as etapas foram construídas de forma participativa, reflexiva e contextualizada, permitindo que os estudantes pudessem participar das decisões, além de desenvolver a autonomia, no sentido de expor suas vontades, esboçar seus interesses e ouvir os colegas. Ao final do projeto, os estudantes puderam expor seus conhecimentos aos colegas da escola e, nesse momento, as pesquisadoras notaram a preocupação desses em relação à apresentação, demonstrando, assim, o senso de comprometimento e 
responsabilidade. Além disso, tal processo contribuiu tanto para a formação intelectual quanto para o raciocínio e o uso do vocabulário adequado para caracterizar os conhecimentos matemáticos e científicos envolvidos nas tarefas.

O estudo de Seibert e Groenwald (2014) investigou a utilização de uma sequência didática eletrônica, que foi desenvolvida utilizando recursos variados, como o aplicativo JClic5 (exercícios e problemas), PowerPoint salvo em HTML (material de estudo) e jogos online, os quais exploraram conceitos matemáticos que objetivavam qualificar a autonomia de um estudante com 19 anos do $7^{\circ}$ ano. As pesquisadoras apontam a recente expansão de pesquisas sobre o funcionamento do cérebro e do aprendizado e que isso deve influenciar as ações também em salas de aula. Nesse sentido, as tecnologias de informação e comunicação (TIC) oferecem, através de estímulos multimodais, diferentes recursos didáticos que devem ser agregados à prática dos professores. Isso porque a intervenção pedagógica cognitiva, realizada com esse estudo de caso, evidenciou sua importância, já que esses estímulos propiciaram um ambiente motivador e facilitador do processo de aprendizagem matemática. Concordamos com Relvas (2008) no sentido de que o estudo da Neurociência Cognitiva é uma competência necessária para o professor do século XXI, frente ao desafio da inclusão de alunos com deficiências nas escolas.

Rossit e Goyos (2009) também cooperam nessa unidade ao analisar a aquisição de relações matemáticas e apresentar um currículo baseado no paradigma de equivalência de estímulos para ensinar estudantes com DI. O procedimento de ensino foi conduzido num ambiente experimental, que dispunha de um microcomputador com monitor colorido, kit multimídia e programa computacional Mestre ${ }^{\circledR}$. Tal ambiente foi montado em uma sala da escola cedida para o desenvolvimento da pesquisa. As pesquisadoras acrescentam que, tradicionalmente, muitos educadores acreditavam que os estudantes com DI esquecem muito rápido o que lhe é ensinado e que, apesar de poderem aprender, eles têm dificuldade em transpor o conhecimento para outras situações ou materiais. Essa pesquisa possibilitou compreender a possibilidade de estudantes com DI evoluírem na aprendizagem, e evidencia a necessidade de os educadores conhecerem os estudantes, avaliar as capacidades por eles apresentadas e utilizar de diferentes recursos para estimular a aprendizagem.

Por sua vez, Brito, Campos e Romanatto (2014), ao investigarem o potencial de jogos para a aprendizagem matemática, enfatizam que os processos de aquisição de conceitos matemáticos precisam ser baseados na possibilidade de tarefas na sala que contribuam para os estudantes desenvolverem novas experiências partindo das já existentes. Assim, o uso de 
jogos em turmas da EJA pode ser motivador e significativo quanto à aquisição de conceitos matemáticos, porém, devem ser abordados de acordo com o planejamento de ensino maior do docente, com os objetivos de ensino e de aprendizagem.

As discussões nessa unidade apresentam que práticas diferenciadas envolvendo jogos, tecnologia de informação e comunicação, material manipulável e recursos diversos evidenciam contribuições para a aprendizagem de Matemática por estudantes com DI. Isso porque, diferente da aplicação direta de conceitos e procedimentos matemáticos, esses tipos de práticas favorecem a articulação com o entorno e o cotidiano dos estudantes, a mediação do professor, a participação dos estudantes e a abstração do pensamento. Para tanto, é fundamental que se respeitem as características cognitivas próprias da idade dos estudantes, que se realize planejamento com o estabelecimento de intencionalidade pedagógica aos recursos e às práticas empregadas e que se promovam ações colaborativas entre professores, incluindo possibilidades interdisciplinares. Para além da aprendizagem matemática, ações com essas características demonstram potencial para estimar o comprometimento, a responsabilidade, a autonomia e a confiança desses estudantes, o que contribui para um desenvolvimento holístico dos mesmos.

\section{O foco nos conceitos matemáticos dos anos iniciais do Ensino Fundamental}

Os artigos de $n^{\circ} 3,4,7,8,13$ e 14 explicitam aspectos particulares sobre os conteúdos matemáticos envolvidos nos estudos, dos quais uma análise transversal evidencia um enfoque no ensino de conceitos matemáticos trabalhados nos Anos Iniciais do Ensino Fundamental. Associando isso aos demais aspectos observados em todos os estudos analisados, percebe-se que estudantes com DI apresentam poucos avanços no que diz respeito a seus conhecimentos matemáticos, ou seja, na maioria dos casos, não acompanham o mesmo conteúdo matemático da série que frequentam.

Os estudantes com SD que trabalharam com o software ITS de Groenwald et al. (2010) apresentaram um bom desempenho nas atividades de quantificadores, contagem, reconhecimento de número, cardinalidade, ordinalidade e algoritmo da adição e subtração com algarismos de um dígito (GROENWALD et al., 2010). O software utilizado possibilitou avanços nos conhecimentos matemáticos, tendo sido construído para estudantes com SD, e reforçam os conhecimentos lógico-matemáticos dos Anos Iniciais do Ensino Fundamental como: classificação, seriação, algoritmo e resolução de problemas. 
O estudante da investigação de Valverde, Sousa e Santos (2017) foi primeiramente observado, sendo identificados os conhecimentos matemáticos que já apresentava, sendo constatado que conseguia verbalizar e identificar os números até nove e quantificar até três, além de apresentar certa dificuldade em contar os dedos das mãos. Os pesquisadores selecionaram o livro "João e o Pé de Feijão" e desenvolveram atividades relacionadas ao livro. Para auxiliar nesse processo, foi construída uma régua numérica como referencial, quantificada com feijões. Foi elaborado também um dominó com feijões e, durante a realização do jogo, sempre que o estudante demonstrava dificuldade em saber qual o número, a régua era utilizada. Considerando a interação dos estudantes com a tecnologia eletrônica, foi disponibilizado um software, que consistia em um jogo de associação da quantidade de borboletas com o número referente à sua quantificação. $\mathrm{O}$ resultado da aplicação da literatura articulado às demais estratégias possibilitou um bom desempenho do estudante quanto à contagem.

Já o estudante da pesquisa de Seibert e Groenwald (2014) não reconhecia pequenas quantidades, contava de forma desorganizada, tinha dificuldade em identificar os números, não conhecia o significado das palavras antecessor e sucessor e confundia ordem crescente e decrescente. Os resultados, observados a partir de uma sequência didática com JClic5, PowerPoint e jogos online, demonstram avanços com os algoritmos das operações com Números Naturais e na resolução de problemas envolvendo o campo aditivo.

Rosso e Dorneles (2012), na pesquisa já mencionada com estudantes com síndrome de X-Frágil (SXF) e Prader-Willi (SPW), perceberam que ambos possuíam o princípio da ordem estável, aproximadamente até 15 , evidenciando a necessidade de intervenção pedagógica para ampliá-lo para quantidades maiores. Por outro lado, ao verificar o princípio da cardinalidade, que se refere ao total de objetos correspondendo ao último nome de número da contagem, identificaram resultados diferentes entre esses estudantes. O estudante com SXF respondeu corretamente ao contar o conjunto total, porém, confundiu-se na hora de falar a cardinalidade, enquanto o estudante com SPW não respondeu corretamente. As pesquisadoras apontam que a compreensão dos princípios de contagem é um conhecimento inicial e fundamental, por isso a importância de se proporcionar intervenções adequadas ainda nos primeiros anos escolares dos estudantes. E ainda, os dados obtidos permitiram analisar que é preciso investigar como esses estudantes constroem conceitos, em especial aqueles relativos à Matemática, para prover recursos específicos que possibilitem suas aprendizagens.

Costa, Picharillo e Elias (2017) analisaram a aplicação de um protocolo de avaliação, 
utilizando materiais como fichas de papelão com numerais, figuras geométricas bidimensionais, Brinquedo Monta Fácil e barbante, além de papel e caneta. O Protocolo continha 34 tarefas de simples resolução, referentes às etapas de aquisição de conceitos e habilidades matemáticas básicas, quais sejam: contagem; produção de sequência; habilidades pré-aritméticas (maior/menor/igual e mais/menos), com objetos unidimensional, bidimensional e tridimensional; uso de problemas orais; e reconhecimento de figuras geométricas. As tarefas foram aplicadas de forma individualizada, para 11 crianças com SD e 10 com desenvolvimento típico, sendo registrado e analisado o número de acertos de cada participante. Os resultados indicaram uma grande diferença entre os participantes com SD (média de 31,2\% de respostas corretas) e os participantes com desenvolvimento típico (média de $97,4 \%$ de respostas corretas). Os autores ressaltam que essa diferença pode não estar relacionada à DI ou a outras deficiências associadas aos participantes com SD, mas, à sua história de vida, principalmente no que se refere ao tipo de atendimento especializado que recebem, às prioridades estabelecidas por professores no que tange ao que devem aprender e, ainda, aos materiais e às tecnologias de ensino empregados nesses processos pedagógicos.

Mediante essa unidade de análise, podemos constatar que o ensino de Matemática a estudantes com DI, nas investigações, volta-se mais para os conceitos ensinados nos Anos Iniciais do Ensino Fundamental. Muitos dos estudantes que foram sujeitos dessas pesquisas não acompanhavam a aprendizagem relacionada à turma que frequentavam. No entanto, práticas pedagógicas com tarefas apropriadas às necessidades e especificidades de cada um, com utilização individualizada e acompanhamento constante e intencional, comprovaram avanços nos conhecimentos matemáticos dos estudantes, sugerindo que são capazes de aprender, mas com temporalidades e necessidades específicas. De todo modo, os resultados sugerem diversas lacunas que necessitam de esclarecimento no que diz respeito objetivamente à aprendizagem de conceitos, ideias e procedimentos matemáticos específicos por alunos com DI, ampliando inclusive àqueles transcendentes aos Anos Iniciais do Ensino Fundamental.

Muitos aspectos interferem na predisposição verificada nas investigações em focar conteúdos dos Anos Iniciais, em detrimento dos demais anos de escolarização. Reforçamos que, na medida em que esses estudantes forem alcançando e ocupando em maior número os outros espaços e níveis de escolarização, como o Ensino Superior, por exemplo, inevitavelmente surgirão demandas mais específicas para esses outros níveis e, consequentemente, veremos pesquisas enfocando também conhecimentos matemáticos de outras séries em maior número. 


\section{O papel do atendimento educacional especializado junto a estudantes com deficiência intelectual}

As pesquisas que estão contempladas nessa unidade são as de $\mathrm{n}^{\circ} 1,11$ e 12 . A expressão "Atendimento Educacional Especializado" (AEE) é conceituada pela Lei de Diretrizes e Bases da Educação - Lei 9394/96 (Cap. V §1º como um serviço destinado a atender às peculiaridades do público-alvo de Educação Especial (BRASIL, 1996). As Diretrizes Nacionais de Educação Especial para a Educação Básica (BRASIL, 2001) estabelecem que o AEE se constitui em um serviço de natureza pedagógica, conduzido por professor especializado. Em 2008, a publicação do documento "Política de Educação Especial na Perspectiva da Educação Inclusiva (PNE-EI)", do MEC, orientou os sistemas de ensino a promoverem respostas às necessidades educacionais especiais dos estudantes, defendendo que a Educação Especial passasse a integrar a proposta pedagógica da escola regular, por meio do desenvolvimento do AEE em Salas de Recursos Multifuncionais - SRM's (BRASIL, 2008b). No Decreto n. ${ }^{\circ} 6.571$ de 2008 (BRASIL, 2008a), os serviços do AEE são referidos como um conjunto de atividades, de recursos pedagógicos e de acessibilidade organizados institucionalmente, prestados de maneira complementar ou suplementar à formação dos estudantes com deficiência, transtornos globais do desenvolvimento e altas habilidades/superdotação, matriculados no ensino regular, devendo integrar a proposta pedagógica da escola, envolver a participação da família e ser realizado em articulação com as demais políticas públicas (BRASIL, 2008a).

Os objetivos do AEE consistem em prover condições de acesso, participação e aprendizagem no ensino regular aos estudantes participantes deste serviço, garantir a transversalidade das ações da Educação Especial na perspectiva inclusiva, fomentar o desenvolvimento de recursos didáticos e pedagógicos que eliminem as barreiras no processo de ensino e aprendizagem, bem como assegurar condições para a continuidade de estudos nos demais níveis de ensino (BRASIL, 2008b).

Neste sentido, o estudo de Costa e Souza (2015) aponta a importância do trabalho com o ensino de Matemática de forma contextualizada e desafiadora. Nota-se, portanto, que na Sala de Recursos Multifuncionais é possível trabalhar com um grupo de estudantes mais reduzido e que compartilhe dificuldades semelhantes e, assim, disponibilizar diferentes situações em que o estudante passe a pensar no que está fazendo e aprendendo, com acessibilidade pedagógica para atender às suas particularidades. Nesse estudo, os estudantes 
conseguiram resolver a situação problema proposta através de interações colaborativas em grupo, que possibilitaram seus desenvolvimentos.

Já no estudo de Mello e Hostins (2018), os professores, junto com os pesquisadores, desenvolveram dinâmicas de estudo e definiram conceitos, procedimentos e estratégias diferenciadas de avaliação pedagógica para uma estudante com DI. O trabalho proposto para a formação envolveu três momentos distintos: diagnóstico, análise crítica da situação e ação/decisão. Para tanto, a análise do Plano de Atendimento Educacional Especializado utilizado no AEE serviu como referência para que o grupo observasse o modelo existente e elaborasse outro plano de trabalho entre esses profissionais. A Lei indica a necessidade de planejar a atuação pedagógica no AEE em articulação com o ensino comum, mas não especifica a necessidade de uma ação planejada, colaborativa e mediada do planejamento, conforme evidenciado no estudo.

Investigando particularmente a prática pedagógica em Salas de Recursos Multifuncionais (SRM), Albuquerque, Mori e Lacanallo (2009) constataram nos registros das fichas dos estudantes que muitos deles foram encaminhados para esses ambientes por apresentarem dificuldades específicas em Matemática. Um dos recursos didáticos mais presente, observado pelas pesquisadoras, foi o uso de jogos. Do total de 25 observações realizadas, em $40 \%$ foram desenvolvidas atividades voltadas à Matemática, nas quais predominou o uso dos jogos. Em 78\% das práticas educativas, o uso de jogos foi trabalhado como uma espécie de passatempo; em apenas $22 \%$ das observações a ação de jogar teve o sentido de recurso de aprendizagem. Concordamos com as pesquisadoras no sentido de que o jogo, ao ser utilizado como recurso de aprendizagem, constitui-se em instrumento importante para o professor. No entanto, deve-se ter o cuidado e a preocupação de utilizá-lo de forma organizada e intencional, como recurso de aprendizagem e desenvolvimento, e não somente como mera fixação do conteúdo trabalhado ou de forma recreativa e lúdica.

O AEE tem um papel fundamental no processo de transformação da escola comum para que ela tenha condições de atender aos estudantes com necessidade educacionais especiais com boa qualidade, disponibilizando recursos e estratégias que auxiliem no processo de aprendizagem. Evidencia-se, contudo, a necessidade de um planejamento fundamentado, intencional, e individualizado aos estudantes, a partir de um trabalho articulado/colaborativo entre os professores do AEE, professores do ensino comum, a equipe escolar e a família em uma parceria contribuindo para o desenvolvimento de uma autoimagem positiva, autonomia e independência do estudante com deficiência. Nesse sentido, é particularmente necessária a 
compreensão do papel da Sala de Recursos Multifuncionais como espaço privilegiado para a condução de práticas diferenciadas de ensino, cuja intencionalidade e características devem ser orientadas pelas necessidades específicas de cada aluno que a frequenta. Desta forma é que se torna possível oferecer AEE condizente às necessidades do estudante com DI.

Não podemos ser ingênuos em conceber que uma escola que precisa de espaços à parte, como a Sala de Recursos Multifuncionais, destinado a alguns estudantes, e não todos, pode ser caracterizada como inclusiva no sentido de que todos vivenciem os mesmos espaços e práticas pedagógicas. Se esses espaços existem, é porque a sala de aula comum não dá conta, ainda, de promover a inclusão por meio das tarefas matemáticas veiculadas. Contudo, também não podemos ser ingênuos em esperar mudanças tão rápidas para as escolas. Esses espaços e qualquer tipo de atendimento especializado numa perspectiva inclusiva ainda são necessários.

\section{Nossas considerações finais}

Neste estudo, de natureza bibliográfica, buscamos compreender quais discussões têm sido privilegiadas nas pesquisas brasileiras que tratam do ensino de Matemática para estudantes com Deficiência Intelectual (DI). As possíveis respostas encontradas não podem ser consideradas totalitárias nem esgotam o assunto, visto que existem outras pesquisas relacionadas que não foram contempladas - a partir dos critérios de seleção empregados -, além dos possíveis vieses decorrentes de nossos olhares revestidos de crenças, concepções e experiências específicas em relação ao ensino de Matemática e à Educação Matemática Inclusiva. Todavia, as inquietações sobressalentes são importantes para pensarmos no ensino desses estudantes e na importância de a educação contemplar o direito de aprendizagem de todos, sem discriminação, sempre respeitando suas diferenças, cuja concretização implica adaptações que legitimem tais características individuais, e não simplesmente as anulem.

Retomando nosso questionamento inicial que orientou o estudo, as pesquisas analisadas apontam a importância de olhar para o estudante com DI como pessoa que, acima de tudo, pode aprender Matemática a partir do momento em que se reconhece e se valoriza suas potencialidades e habilidades, aliadas a um planejamento intencional que priorize estratégias diversificadas e coadunadas com suas especificidades. Dessa maneira, apontamos a necessidade de que as formações docentes, iniciais ou continuadas, incluam nas suas discussões os estudantes com DI, bem como estratégias metodológicas para o ensino de 
Matemática numa perspectiva inclusiva. Nesse sentido, é fundamental conhecer o diagnóstico do estudante com DI, para saber das especificidades e poder traçar planos de ensino que contemplem as suas necessidades, e não para justificar a não aprendizagem.

Identificamos nas investigações uma preponderância sobre o ensino de Matemática dos Anos Iniciais e, a partir do nosso filtro de busca, não foram encontrados estudos envolvendo Educação Infantil, Ensino Médio e Educação Superior. Isso pode decorrer de ainda termos poucos sujeitos com DI em alguns desses níveis de ensino (principalmente os mais avançados), seja pelas capacidades de todos os envolvidos ou pela negligência do sistema escolar. Dessa forma, esse aspecto aponta um campo amplo a ser explorado nas pesquisas.

Em relação às nossas unidades de análise, foi possível notar o uso de diversos recursos como: materiais manipuláveis, ambientes digitais com softwares, jogos etc., sendo que esses tipos de recursos, quando usados atrelados aos objetivos de ensino e aprendizagem de Matemática e adaptados às necessidades individuais, facilitam, na maioria das vezes, a compreensão do conceito trabalhado com o estudante com DI. Assim, esses recursos são importantes no ensino e aprendizagem de estudantes com DI de maneira semelhante aos demais estudantes, como já apontado na literatura de Educação Matemática, independentemente de estar ou não vinculada às pesquisas no campo da Educação Especial.

Notamos, nas pesquisas aqui identificadas, a importância de que haja diálogo e compartilhamento entre os saberes de profissionais tanto da Educação Especial quanto aqueles que atuam nas salas de aula comuns. Somente articulando todos os agentes envolvidos no processo e os conhecimentos inerentes a cada um desses profissionais que se constitui uma escola inclusiva, com AEE adequado, com SRM exercendo sua devida e essencial função. Afinal de contas, sem diálogo e compartilhamento de saberes, não será possível criar um ambiente contínuo, sem solavancos, de inclusão, ou seja, não será possível pensar numa escola que se almeje inclusiva de maneira completa, focando, principalmente no ensino e na aprendizagem de todos os nossos estudantes.

Salientamos também, como consequência das leituras visitadas, a importância do diagnóstico precoce da DI (para que as medidas sejam mais adequadas e rápidas possíveis) e o respeito aos tempos diferentes de todos os estudantes, com destaque para aqueles com DI. Somos, inclusive, favoráveis ao diálogo com profissionais de outros campos, como os terapeutas em caso de estudantes atendidos, não com o objetivo de sobrepor a visão médica à pedagógica no interior da escola, mas de conhecer melhor nossos estudantes. 
Finalmente, este foi apenas nosso processo de releitura das produções acerca do ensino de Matemática para pessoas com DI, com o qual pretendemos contribuir com novas investigações, ampliando as discussões e o número de pessoas interessadas nessa temática. Ao trazermos um panorama das pesquisas, entendemos que esse olhar mais amplo permite identificar lacunas e também convergências. Porém, acima de tudo, ele constitui um alerta a todos para o fato de que cada estudante é único, mesmo que tenha uma deficiência em comum. Tal compreensão é fundamental na orientação de qualquer ação pedagógica e se torna ainda mais essencial quando pensamos o ensino de estudantes com DI, particularmente no campo de Matemática.

\section{Referências}

ALBUQUERQUE, R. A.; MORI, N. R.; LACANALLO, L. F. Salas de recursos e o uso de jogos para o ensino de conceitos matemáticos. Revista de Educação Especial. Santa Maria, n. 34, v. 22, p. 155-164. 2009.

AMERICAN PSYCHIATRIC ASSOCIATION et al. Intellectual disability fact sheet-DSM5. Arlington, VA: American Psychiatric Association, 2013.

BRASIL. Ministério da Educação. Lei de Diretrizes e Bases da Educação Nacional no 9394/96. Brasília, 1996.

BRASIL. Ministério da Educação. Diretrizes Nacionais para Educação Especial na Educação Básica. Brasília, 2001.

BRASIL. Ministério da Educação. Decreto nº 6.571 de 17 de set. de 2008. Brasília, 2008a.

BRASIL. Ministério da Educação. Política Nacional de Educação Especial na Perspectiva da Educação Inclusiva. Brasília: MEC/SECADI, 2008b. Disponível em:

$<$ http://portal.mec.gov.br/index.php?option=com_docman\& view $=$ download\&alias $=16690$ politica-nacional-de-educacao-especial-na perspectiva-da-educacao-inclusiva05122014\&Itemid=30192> . Acesso em: 22 maio 2017.

BRASIL. Ministério da Educação. Conselho Nacional de educação. Resolução no 4, de 2 de outubro de 2009. Institui Diretrizes Operacionais para o Atendimento Educacional Especializado na Educação Básica, modalidade Educação Especial. Brasília: MEC/CNE, 2009. Disponível em: <http://portal.mec.gov.br/dmdocuments/rceb004_09.pdf >. Acesso em: 22 maio 2017.

BRITO, J.; CAMPO, J. A. P. P.; ROMANATTO, M. C. Ensino da matemática a alunos com deficiência intelectual na educação de jovens e adultos. Revista Brasileira de Educação Especial. Bauru, n. 4, v. 20, p. 525-540, 2014. 
CARRAHER, T.; SCHLIEMANN, A.; CARRAHER, D. Na vida dez, na escola zero. Recuperado em http://www.inep.gov.br/PESQUISA/BBE-ONLINE/det.asp? cod=49906\& type=M São Paulo: Cortez, 2001.

COSTA, M. P. R. Fundamentos matemáticos e cognitivos para o ensino de matemática para alunos deficientes mentais. Temas psicol. n.1, vol.3, pp. 69-82. 2018

COSTA, A.; PICHARILLO, A. D. M.; ELIAS, N. C. Avaliação de habilidades matemáticas em crianças com síndrome de Down e com desenvolvimento típico. Revista Brasileira de Educação Especial. Bauru, n. 1, v. 23, p. 255-272, 2017.

COSTA, C. S.; SOUZA, M. C. de A. R. O aluno com Deficiência Intelectual e a Resolução de Problemas. Educação Matemática em Revista. Brasília, n. 47, p. 29, 2015.

FREITAS, P. M.; RIBEIRO, D. O. Neuroplasticidade na Educação e Reabilitação Cognitiva da Deficiência Intelectual. Revista de Educação Especial. Santa Maria, v. 32, p. 469-483, 2019.

GIL, A. C. Como elaborar projeto de pesquisa. 4. ed. São Paulo: Atlas, 2002.

GROENWALD, C. L. O.; SEIBERT, E. T.; MORENO, L.; MUÑOZ, V.; HORA, G. S.; MATOS, A. C.; SALLENAVE, J. A. C.; CAFESEIRO, J. S. Eixos convergentes na aprendizagem matemática de alunos com Síndrome de Down. Revemat - Revista Eletrônica de Educação Matemática - UFSC. n. 1, v. 5, p. 25-37, 2010.

MELLO, A. F. G.; HOSTINS, R. C. Construção mediada e colaborativa de instrumentos de avaliação da aprendizagem na escola inclusiva. Revista de Educação Especial. Santa Maria, n. 63 , v. 31, p. 1025-1038, 2018.

MIRANDA, A. D.; PINHEIRO, N. A. M. O ensino da matemática ao deficiente intelectual: projetos de trabalho em uma perspectiva contextualizada e interdisciplinar. Revista de Educação Especial. Santa Maria, n. 56, v. 29, p. 695-708, 2016.

MIZUKAMI, M. da G. N. Ensino: as abordagens do processo. São Paulo: Editora Pedagógica e Universitária, 1986.

MODENUTTE, S. C.; MONTEIRO, M. A. A.; SUSIKI, P. A. Fenomenologia e Filosofia Existencialista de Heidegger no estudo de um deficiente intelectual e suas dificuldades na aprendizagem de matemática. Revista Brasileira de Ensino de Ciência e Tecnologia UTFPR. n. 1, v. 12, p. 450-461, 2019.

MORAES, R. Análise de conteúdo. Revista Educação, Santa Maria, v. 22, n. 37, p. 7-32, 1999.

RELVAS, M. P. Neurociência na aprendizagem escolar. Rio de Janeiro: Wak, 2008. 
RODRIGUES, D. Inclusão e Educação: doze olhares sobre a Educação Inclusiva. São Paulo: Sumos Editoriais, 2006.

ROSSIT, R. A. S.; GOYOS, C. Deficiência intelectual e aquisição matemática: currículo como rede de relações condicionais. Psicol. Esc. Educ. (Impr.) [online]. n. 2, v. 13, p. 213$225,2009$.

ROSSO, T. R. F.; DORNELES, B. V. Contagem numérica em estudantes com síndromes de X-Frágil e Prader-Willi. Revista Brasileira de Educação Especial, Bauru, n. 2, v. 18, p. 231244, 2012.

SEIBERT, E. S.; GROENWALD, C. L. O. Contribuições das neurociências para a educação matemática de uma pessoa com necessidades educativas especiais intelectivas. Revista de Educação Especial. Santa Maria, n. 48, v. 27, p. 233-248, 2014.

SILVA, M. C. L.; OLIVEIRA, M. S. Concepção dos professores sobre a apropriação de conhecimentos matemáticos por crianças com síndrome de Down. Revista de Educação Especial. Santa Maria, n. 37, v. 23, p. 65, 2010.

VALVERDE, V.; SOUSA, P. B.; SANTOS, P. Ensino de números naturais associado à literatura infantil para alunos com Síndrome de Down. Revista Paranaense de Educação Matemática - Universidade Estadual do Paraná. n. 6, v. 11, p. 233-258, 2017.

ZUFFI, E. M. A inclusão de alunos portadores de deficiência intelectual e/ou paralisia cerebral em salas de aula regulares de matemática. Jornal Internacional de Estudos em Educação Matemática. Uniban, São Paulo, n. 17, v. 2, 2014. 